\title{
Effectiveness of high-intensity interval training on glycemic control and cardiorespiratory fitness in patients with type 2 diabetes: a systematic review and meta-analysis
}

\author{
Jing-xin Liu ${ }^{1} \cdot \operatorname{Lin} \mathrm{Zhu}^{1,2} \cdot$ Pei-jun $\mathrm{Li}^{1} \cdot \mathrm{Ning} \mathrm{Li}^{1} \cdot$ Yan-bing Xu${ }^{3}$ \\ Received: 4 May 2018 / Accepted: 14 July 2018 / Published online: 30 July 2018 \\ (C) The Author(s) 2018
}

\begin{abstract}
Aims The aim of this systematic review and meta-analysis was to quantify the effect of high-intensity interval training (HIIT) on glycemic control and cardiorespiratory fitness compared with moderate-intensity training (MICT) and no training at all in patients with type 2 diabetes (T2D).

Methods Relevant articles were sourced from PubMed, Embase, the Web of Science, EBSCO, and the Cochrane Library. Randomized-controlled trials were included based upon the following criteria: participants were clinically diagnosed with T2D, outcomes that included glycemic control (e.g., hemoglobin A1c); body composition (e.g., body weight); cardiorespiratory fitness (e.g., $\mathrm{VO}_{2 \text { peak }}$ ) are measured at baseline and post-intervention and compared with either a MICT or control group. Results Thirteen trials involving 345 patients were finally identified. HIIT elicited a significant reduction in BMI, body fat, $\mathrm{HbA1c}$, fasting insulin, and $\mathrm{VO}_{2 \text { peak }}$ in patients with type 2 diabetes. Regarding changes in the body composition of patients, HIIT showed a great improvement in body weight (mean difference: $-1.22 \mathrm{~kg}, 95 \%$ confidence interval [CI] -2.23 to $-0.18, P=0.02$ ) and body mass index (mean difference: $-0.40 \mathrm{~kg} / \mathrm{m}^{2}, 95 \% \mathrm{CI}-0.78$ to $-0.02, P=0.04$ ) than MICT did. Similar results were also found with respect to HbA1c (mean difference: $-0.37,95 \% \mathrm{CI}-0.55$ to $-0.19, P<0.0001$ ); relative $\mathrm{VO}_{2 \text { peak }}$ (mean difference: $3.37 \mathrm{ml} / \mathrm{kg} / \mathrm{min}, 95 \%$ CI 1.88 to $4.87, P<0.0001$ ); absolute $\mathrm{VO}_{2 \text { peak }}$ (mean difference: $0.37 \mathrm{~L} / \mathrm{min}, 95 \% \mathrm{CI} 0.28$ to $0.45, P<0.00001$ ).
\end{abstract}

Conclusions HIIT may induce more positive effects in cardiopulmonary fitness than MICT in T2D patients.

Keywords High-intensity interval training · Glycemic control · Cardiorespiratory fitness · Type 2 diabetes

\section{Introduction}

Type 2 diabetes (T2D) is a metabolic disease characterized by hyperglycemia resulting from a resistance to insulin or a relative insulin insufficiency that can induce cardiovascular disease and lead to cardiovascular deterioration. According to epidemiological survey results, more than 422 million people worldwide were living with diabetes

Lin Zhu

40848567@qq.com

1 School of Kinesiology, Shanghai University of Sport, Shanghai 200438, China

2 Guangzhou Sport University, Guangzhou 510500, China

3 Department of Child Health Care and Rehabilitation, Lanzhou University Second Hospital, Lanzhou 730030, China in 2014 [1], with a predicted prevalence of 552 million by 2030 [2]. Because of the growing economic and social burdens associated with T2D treatment, effective and accessible lifestyle interventions for people with T2D have never been more important. Exercise intervention is recognized as an integral concept for lifestyle intervention in T2D patients [3, 4], and it has been recommended by both the American Diabetes Association and the American College of Sports Medicine that patients should perform at least $150 \mathrm{~min} /$ week of moderate-to-vigorous aerobic exercise $[5,6]$. Abundant evidence from randomized-controlled trials (RCTs) shows the benefits of aerobic exercise in glycemic control; for example, it reduces fasting glucose and improves insulin sensitivity, both of which help to alleviate the development of diabetes complications and mortality [7-10]. Furthermore, a recent meta-analysis demonstrated that aerobic exercise training is associated with a decrease in $\mathrm{HbA} 1 \mathrm{c}$, insulin resistance, and fasting 
glucose, and suggested that high-intensity aerobic exercise is superior to lower intensity exercise in improving cardiorespiratory fitness in T2D patients [11]. However, the majority of patients do not typically achieve the recommended level of physical activity, despite the fact that increases in physical activity level can improve glycemic control and cardiorespiratory fitness in T2D patients. In addition, a lack of time has been identified as one of the key barriers preventing patients from performing sufficient physical activity, which means that patients must participate in more time-efficient training programs to achieve optimized outcomes.

High-intensity interval training (HIIT), therefore, appears to be a feasible and time-efficient alternative exercise protocol to aerobic exercise: it involves alternating, repetitive short bouts of high-intensity exercise interspersed with less active or passive recovery periods. Numerous recent studies have shown HIIT to be superior in improving health benefits compared with lower intensity aerobic exercise in a variety of populations [12-14]. Støa et al. [15] found that people with T2D who performed a supervised HIIT program at an intensity of $85-95 \%$ of their maximal heart rate with $52 \% \mathrm{VO}_{2 \text { peak }}$ interval experienced a significant increase in $\mathrm{VO}_{2 \text { peak }}$ and a reduction in hemoglobin A1c (HbAlc), body weight, and body mass index (BMI) compared with those who performed moderate-intensity continuous training (MICT), though no significant changes in insulin resistance or blood lipid levels were found. Karstoft et al. [16] compared the efficacy of HIIT with energy expenditurematched continuous-walking training in people with T2D and observed greater improvements in $\mathrm{VO}_{2 \text { peak }}$, body weight, fat mass, and glycemic control with the former. Mitranun et al. [17] also found that HIIT improved HbA1c, maximal aerobic capacity, and other cardiovascular risk factors in T2D patients, even if the total exercise time was reduced to half of that recommended. Similar to the current study, a recent meta-analysis by Jelleyman et al. demonstrated that HIIT is more effective than MICT for improving insulin sensitivity and cardiorespiratory fitness in healthy individuals [18]. However, this study did not determine the suitability of HIIT in individuals with T2D. Indeed, although a few RCTs have demonstrated the efficiency of HIIT in the prevention and treatment of T2D patients, no consensus has yet been reached that HIIT is a superior training protocol for the improvement of glycemic control, body composition, and cardiorespiratory fitness compared with moderate-intensity continuous aerobic training among patients with T2D. Therefore, we performed a meta-analysis to determine the impact of HIIT on body composition, glycemic control, and cardiorespiratory fitness, and to compare it to that of MICT and that of no intervention in randomized-controlled trials in T2D patients, which we hope can provide clinical evidence to enable patients to achieve optimal outcomes.

\section{Patients and methods}

\section{Search strategy}

The databases which we searched included PubMed, the Web of Science, EBSCO, Embase, and the Cochrane Library. All of the databases were searched from their date of inception until April 2018. We included only studies written in English. We used combined key phrases and Medical Subject Heading (MeSH) terms as follows: "type 2 diabetes mellitus," "diabetes mellitus, type II," "type 2 diabetes," "T2D," "T2DM," "high-intensity interval training," "highintensity aerobic interval exercise," "high-intensity interval training," "aerobic interval training," "high-intensity intermittent exercise," "HIT," and "HIIT." Supporting information appendix in $\mathbf{S 1}$ gives a detailed description of the search strategy. In addition, the reference lists of included studies and reviews were also examined for additional potentially eligible studies.

\section{Inclusion and exclusion criteria}

\section{Type of study}

This review included studies with randomized-controlled trials. We excluded matched controlled trial designs, uncontrolled trials, observational studies, and animal studies.

\section{Type of participant}

The study participants were clinically diagnosed with type 2 diabetes. Patients with type 1 diabetes and gestational diabetes were excluded. There was no limitation on the age, gender, or ethnicity of the study participants.

\section{Intervention variables and outcome measures}

The studies included here were required to report at least one outcome measure, measured at baseline and post-intervention, and compared to either a moderate-intensity exercise intervention or control group. The HIIT program had to be prescribed at least two times per week for 4 weeks, with moderate-intensity continuous training or another treatment (e.g., drug therapy) as the control group.

\section{Primary outcomes}

Outcome measures included glycemic control (e.g., HbA1c, fasting glucose, and fasting insulin); body composition [e.g., body weight, BMI, body fat (\%), and waist circumference]; cardiorespiratory fitness (e.g., $\mathrm{VO}_{2 \text { peak }}$ ). The criteria which 
we used complied with the PICO concept (patient/problem/ population; intervention; comparison/control/comparator; outcome). For articles reported in more than two publications, only one full copy was used for meta-analysis. Abstracts presented at academic conferences, case reports, observational studies, examples of animal research, and studies of which the full text could not be obtained were excluded.

\section{Evaluation of bias and quality assessment}

The risk of bias and methodological quality of the included trials were assessed independently by two reviewers (Liu and Li), who used the Cochrane Collaboration's tool [19] to check for concealed allocation, allocation concealment, blinding, incomplete outcome data, selective reporting, and other biases. Each reviewer was required to award one of three grades (either unclear, low risk, or high risk) to each item. The Grading of Recommendations Assessment, Development, and Evaluation (GRADE) system [20] was used to assess the quality of the evidence from very low to high based on risk of bias, inconsistency, indirectness, imprecision, and publication bias. A third reviewer was consulted if any disagreement occurred.

\section{Data extraction}

The two investigators assessed each article's title or abstract for eligibility. When a disagreement happened, a third investigator participated in a discussion to reach a final consensus. For studies that met the inclusion criteria, full papers were obtained for further analysis. The two authors independently extracted data from the published works using standard data extraction forms. If there were any inconsistencies in the process of data extraction, the two authors would check the original text and reach an agreement through discussion or through verification by a third author. Information on trial design, characteristics of the patients, HIIT protocol, and relevant results was noted according to a redesigned form. We recorded the name of the first author and the year of publication; the number of patients/participants and their ages, gender, and BMIs; the duration of diagnosis; and the experimental and control interventions (e.g., exercise intensity and duration, interval intensity and duration, session time, and duration in weeks). When data were insufficient or inapplicable, we attempted to contact the authors by e-mail or used an equation to reveal all available data.

\section{Data analysis}

The Review Manager software (RevMan 5.3; Cochrane, London, UK) was used to conduct the meta-analysis. The statistical heterogeneity of the treatment effect among the included studies was assessed using the chi-squared test and $I^{2}$ test. A threshold of $P<0.10$ was considered to be statistically significant and an $I^{2}$ value $>50 \%$ was indicative of high heterogeneity. We used the weighted mean difference (MD) or standardized MD (SMD) with $95 \%$ confidence intervals (CIs) for summary statistics and derived such for the comparison of HIIT with MICT or other treatment methods. MD was used when all studies reported the same outcome using the same scale, while SMD was used when studies reported different units or scales for the outcome. If heterogeneity did not exist between studies, we incorporated a fixed-effects model approach to combined outcome measures. A randomeffects model was used when there was a large degree of heterogeneity between studies. To account for within-group intervention effect sizes, we used fixed-effects modeling to estimate the change from baseline. Potential heterogeneity sources were identified by sensitivity analyses conducted by omitting one study successively and comparing the influence of each study on the overall pooled estimate if $I^{2}>50 \%$.

Data were analyzed using the change from baseline for both groups. If the study did not contain change data, we used the following two equations for conversion:

$M=\left|M_{1}-M_{2}\right|$,

where $M$ is the effect mean, $M_{1}$ is the mean of the baseline, and $M_{2}$ is the end value mean;

$S^{2}=S_{1}^{2}+S_{2}^{2}-2 \times R \times S_{1} \times S_{2}$,

where $S$ is the standard deviation of the effect, $S_{1}$ is the standard deviation of the baseline value, $S_{2}$ is the final standard deviation, and $R$ is constant ( 0.4 or 0.5 ).

\section{Results}

\section{Search results}

The initial database searches returned a total of 484 articles (PubMed, $n=84$; EMBASE, $n=30$; The Cochrane Library, $n=63$; EBSCO, $n=30$; the Web of Science, $n=277$ ) that were each screened and evaluated for eligibility based on their respective titles only. Following removal of duplicates, 421 articles underwent further identification and screening. In total, 378 non-relevant articles were excluded after screening the titles and abstracts. Of the remaining articles, 43 were selected to be read in full. At this point, 30 additional articles were excluded for varying reasons (e.g., the study was not randomized, there were reduplicative participants, the study was observational in nature, the research was performed on animals, the study was presented at an academic conference, and/or the study had no required data), rendering a final sample of 13 papers. Figure 1 describes the study selection flow. 
Fig. 1 Flowchart of the study selection process

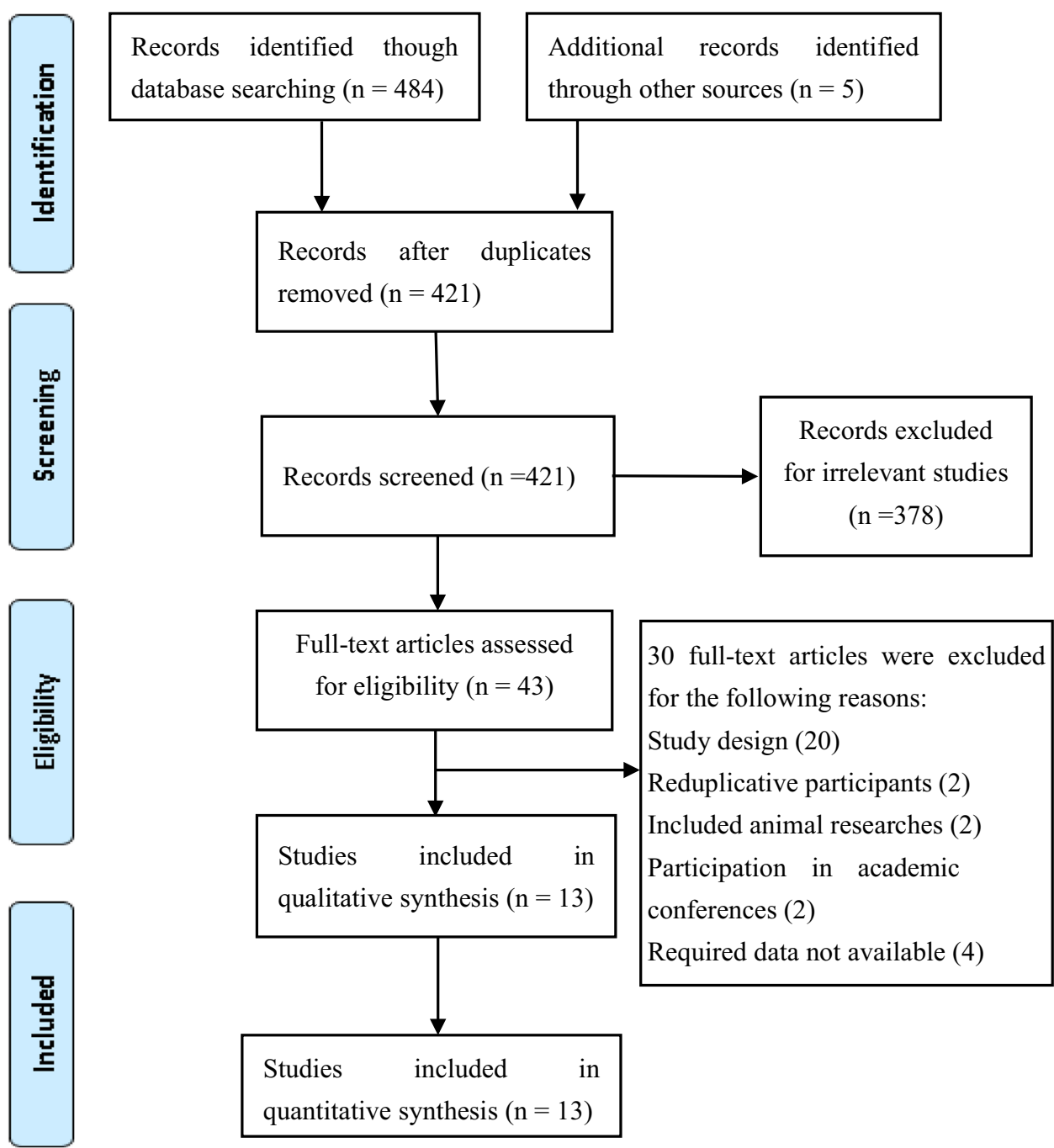

\section{Characteristics of included trials}

A total of 345 participants were included in the analysis, of which $163(47.2 \%)$ participants underwent a HIIT intervention. The characteristics of the study participants, the HIIT training protocols used, and the main results from the included studies are described in Table 1. The countries or regions of publication were mainly the United Kingdom $(n=2)$, Norway $(n=2)$, the Republic of Korea $(n=1)$, Chile $(n=1)$, Denmark $(n=2)$, France $(n=1)$, Thailand $(n=1)$, Australia $(n=1)$, Italy $(n=1)$, and Canada $(n=1)$. The main HIIT intervention ranged in duration from 11 to 16 weeks (16 weeks in 4 studies, 12 weeks in 8 studies, and 11 weeks in 1 study) and occurred two-to-five times weekly (median: three times). Total training duration per session ranged from $30 \mathrm{~s}$ to $4 \mathrm{~min}$, and interval duration ranged from $30 \mathrm{~s}$ to $3 \mathrm{~min}$.

\section{Risk of bias among the selected articles}

The 13 studies were assessed for risk of bias; the evaluation results are shown in Table 2. Among the included studies, the method of randomization was only clearly stated in four studies $[21,25,26,28]$, while three reported allocation concealment [25, 26, 28], five blinded participants or personnel $[15,16,21,23,28]$, and three did not employ assessor blinding [22, 24, 27]. Only one study did not clearly state complete outcomes data and employed selective reporting [22]; no other bias in all studies. The evaluation of the overall quality of evidence and results is shown in Table 4, and the level of evidence for RCTs is 


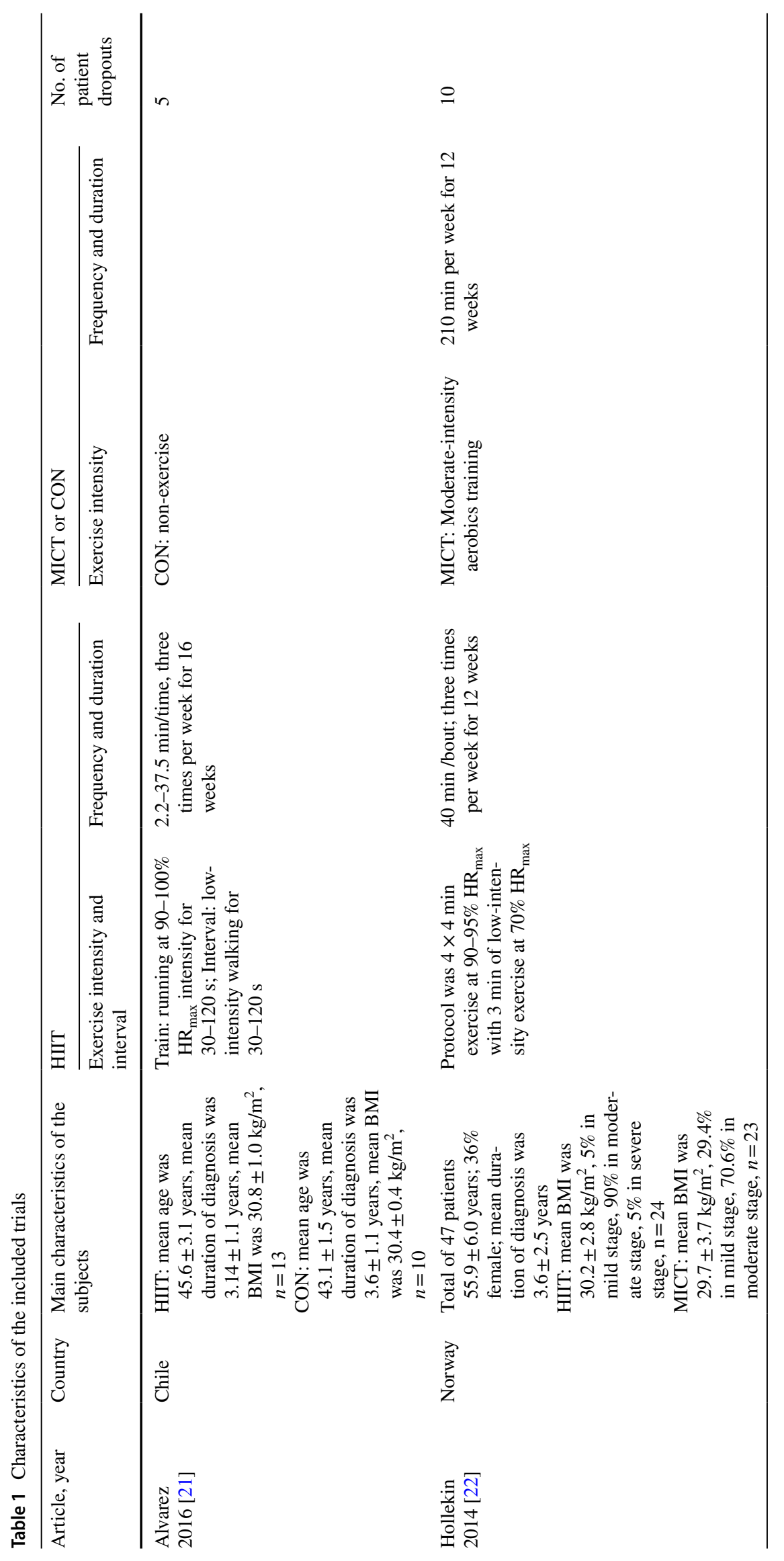




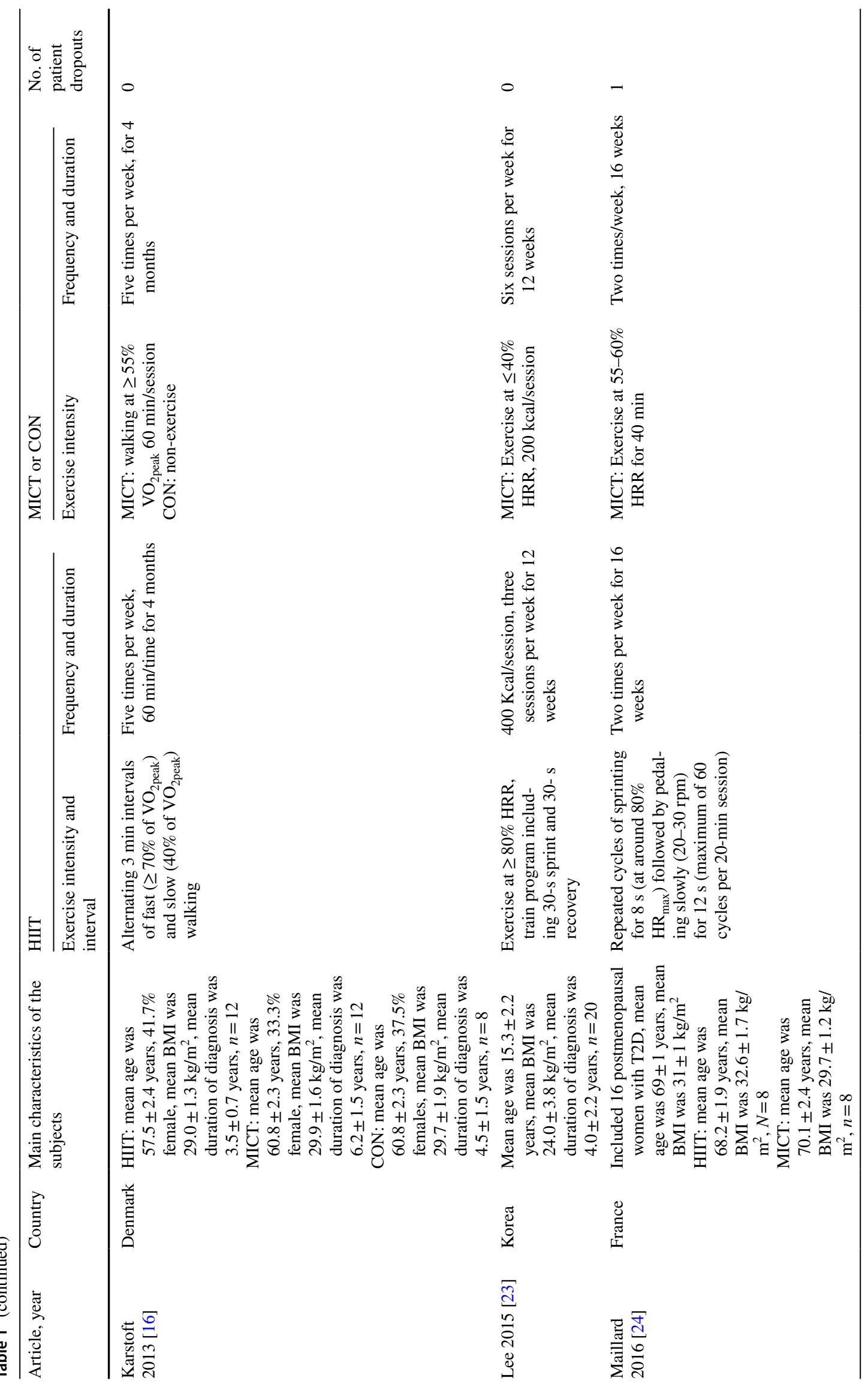




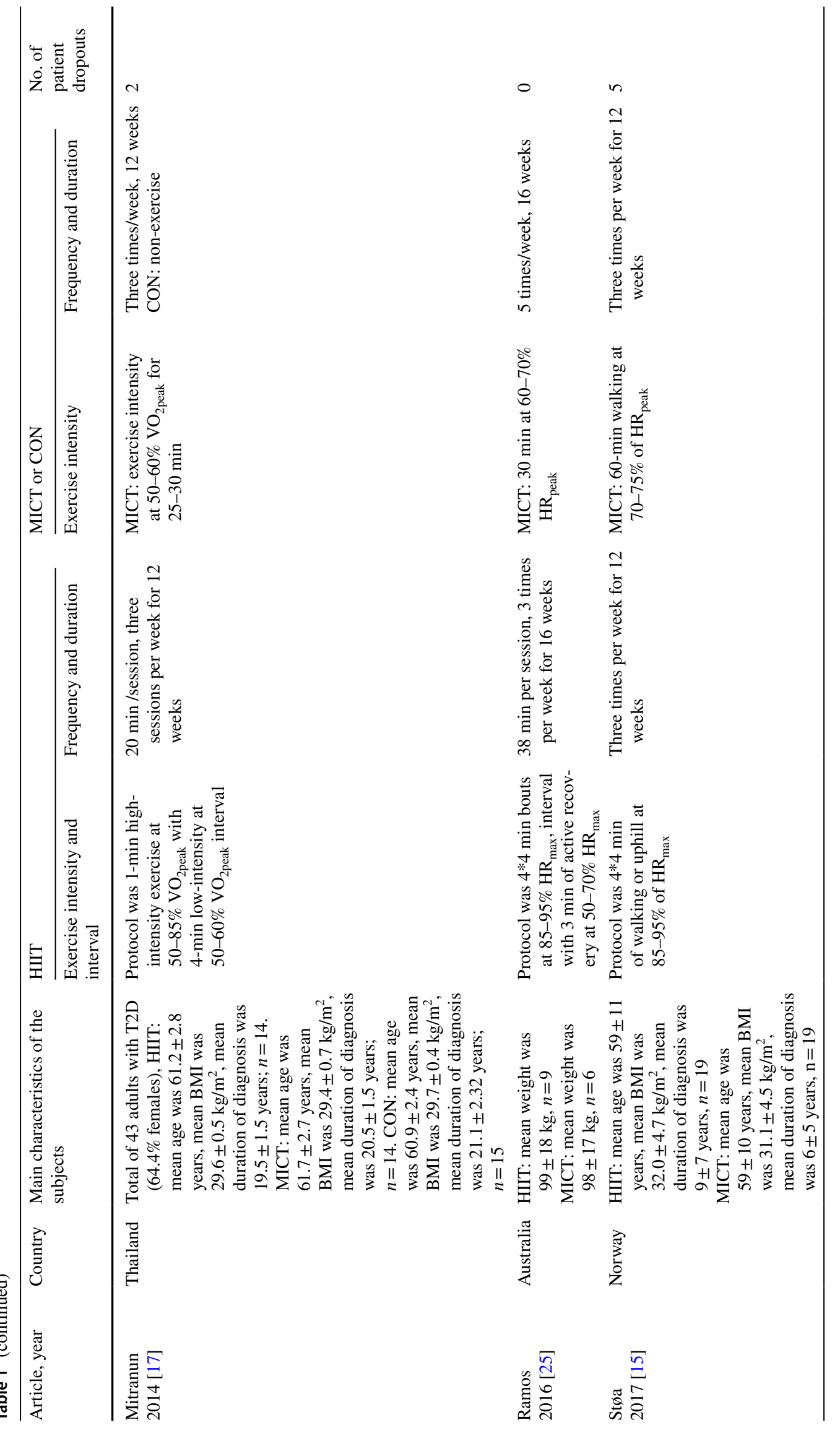




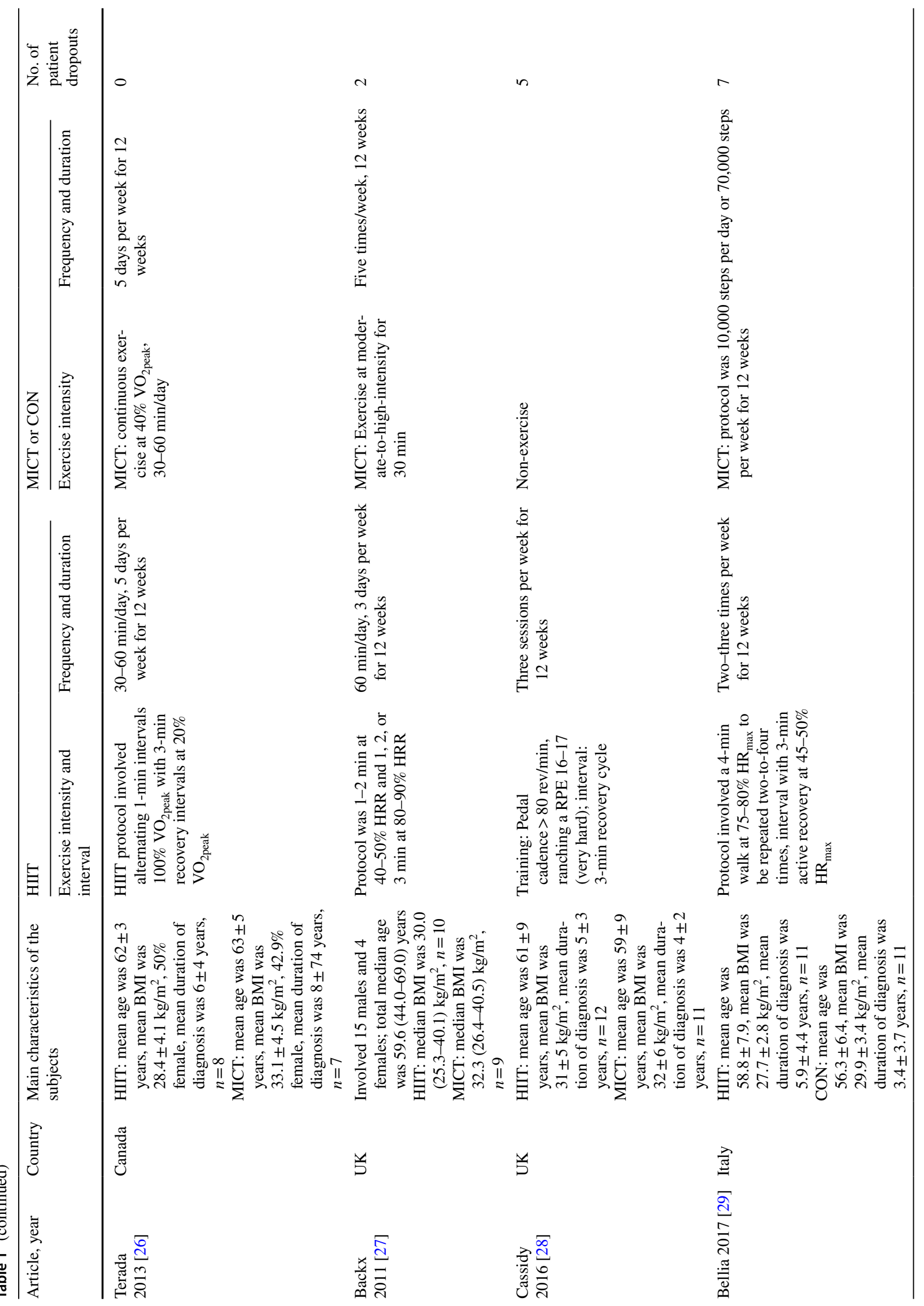




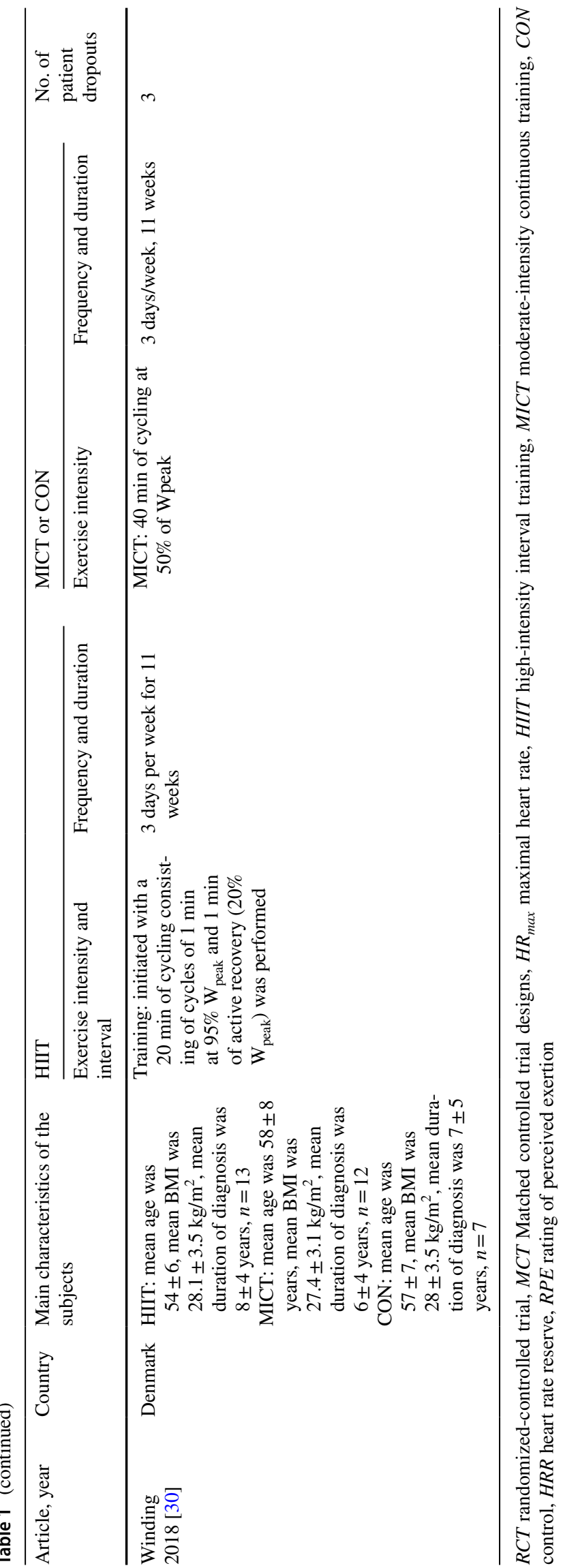

downgraded due to inconsistency and imprecision in most of the studies.

\section{Effects of HIIT on body composition}

The included studies assessed body weight (11/13; 84.6\%); BMI $(11 / 13 ; 84.6 \%)$; body fat $(6 / 13 ; 46.2 \%)$; waist circumference $(7 / 13 ; 53.8 \%)$ as outcomes. Of these, $8 / 11(72.7 \%$ of body weight studies); 8/11 (72.7\% of BMI studies); 5/6 ( $83.3 \%$ of body fat studies); 6/7 (85.7\% of waist circumference studies) compared HIIT to MICT. The meta-analyses showed (Table 3 ) a significant reduction in body weight of $1.22 \mathrm{~kg}[95 \% \mathrm{CI}-2.23$ to $-0.18, P=0.02]$ for patients in the HIIT group as compared with those in the MICT group. Furthermore, in comparison with baseline, there was a reduction in $\mathrm{BMI}$ of $0.85 \mathrm{~kg} / \mathrm{m}^{2}(95 \% \mathrm{CI}-1.57$ to -0.12 , $P=0.02$ ) (Table 3), and, as compared with the MICT group, the reduction was $0.40 \mathrm{~kg} / \mathrm{m}^{2}(95 \% \mathrm{CI}-0.78$ to -0.02 , $P=0.04$ ) (Table 3 ). In addition, as compared with baseline, there was a reduction in body fat of $1.86 \%$ (95\% CI -3.68 to $-0.04, P=0.02$ ) (Table 3), but the reduction was not statistically significant as compared with that in the MICT group. In addition, there was no significant difference in the waist circumference reduction following HIIT versus MICT or at baseline (Table 3 ).

\section{Effects of HIIT on glycemic control}

Ten studies with 220 patients assessed HbA1c. Of these, nine studies compared changes in HbA1c in HIIT groups to those in MICT groups, while only three studies compared such to changes in CON groups. Relative to baseline, there was a significant reduction in HbA1c (SMD: $-0.29,95 \%$ CI -0.55 to $-0.04, P=0.02$ ) (Fig. 2a; Table 3). Compared with MICT, the reduction was $0.37 \%$ (95\% CI -0.55 to $-0.19, P<0.0001$, Fig. 2a). However, in comparison with a control intervention, a non-significant change in $\mathrm{HbAlc}$ of $-0.39 \%$ (95\% CI -0.81 to $0.02, P<0.06$, Fig. 2 b) was found. As compared with baseline, there was a significant reduction in fasting insulin (SMD: $-0.46,95 \% \mathrm{CI}-0.81$ to $-0.11, P=0.01$, Table 3$)$. However, this reduction was not significantly different as compared with that in the control intervention or MICT groups (Table 3). No significant difference in the fasting glucose or HOMA-IR (homeostatic model assessment of insulin resistance) was found for participants in the HIIT group as compared with those in the MICT group (Table 3). We further used sensitivity analysis in HOMA-IR because of the larger heterogeneity $\left(I^{2}=73 \%\right)$ within the group. The results of sensitivity analysis showed that the heterogeneity $\left(I^{2}=0 \%\right)$ was significantly reduced after exclusion of Lee 2015, but there was no significant change in results. 
Table 2 Risk-of-bias assessment for the included studies

\begin{tabular}{|c|c|c|c|c|c|c|c|}
\hline \multirow[t]{2}{*}{ Study } & \multirow{2}{*}{$\begin{array}{l}\text { Random sequence } \\
\text { generation }\end{array}$} & \multirow{2}{*}{$\begin{array}{l}\text { Allocation } \\
\text { concealment }\end{array}$} & \multicolumn{2}{|l|}{ Blinding } & \multirow{2}{*}{$\begin{array}{l}\text { Incomplete } \\
\text { outcome data }\end{array}$} & \multirow[t]{2}{*}{ Selective reporting } & \multirow[t]{2}{*}{ Other bias } \\
\hline & & & $\begin{array}{l}\text { Participants or } \\
\text { personnel }\end{array}$ & $\begin{array}{l}\text { Outcome } \\
\text { assessment }\end{array}$ & & & \\
\hline Alvarez [21] & Low & Unclear & Low & Low & Low & Low & Low \\
\hline Hollekin [22] & Unclear & Unclear & Unclear & Unclear & Unclear & Unclear & Low \\
\hline Karstoft [16] & Unclear & Unclear & Low & Low & Low & Low & Low \\
\hline Lee [23] & Unclear & Unclear & Unclear & Low & Low & Low & Low \\
\hline Maillard [24] & Unclear & Unclear & Unclear & Unclear & Low & Low & Low \\
\hline Mitranun [17] & Unclear & Unclear & Unclear & Low & Low & Low & Low \\
\hline Ramos [25] & Low & Low & Low & Low & Low & Low & Low \\
\hline Støa [15] & High & High & Low & Low & Low & Low & Low \\
\hline Terada [26] & Low & Low & High & Low & Low & Low & Low \\
\hline Backx [27] & High & Unclear & Unclear & Unclear & Low & Low & Low \\
\hline Cassidy [28] & Low & Low & Low & Low & Low & Low & Low \\
\hline Bellia [29] & Unclear & Unclear & Unclear & Low & Low & Low & Low \\
\hline Winding [30] & Unclear & Unclear & Unclear & Low & Low & Low & Low \\
\hline
\end{tabular}

\section{Effects of HIIT on lipid control}

Seven studies assessed low-density lipoprotein (LDL) cholesterol as an outcome. Of these, five studies compared the change in the HIIT group to that in the control group and six studies compared the change in the HIIT to that in the MICT group. There was also a significant reduction in LDL cholesterol (MD: $-0.25 \mathrm{mmol} / \mathrm{L} 95 \% \mathrm{CI}-0.46$ to -0.04 , $P=0.02$ ) with HIIT versus with the MICT group (Table 3 ). Unfortunately, there was no significant change in total cholesterol as compared with both the control and MICT groups and a similar result was found with respect to high-density lipoprotein (HDL) cholesterol. LDL cholesterol did not differ significantly between the HIIT group and the control group. Because studies comparing HIIT with control interventions in relation to LDL and HDL cholesterol showed significantly more heterogeneity, we conducted sensitivity analysis that showed that the studies heterogeneity changed significantly $\left(I^{2}=20 \%\right.$ in LDL cholesterol, $I^{2}=0$ in HDL cholesterol) after the removal of Alvarez 2016, but there were no significant changes in the results.

\section{Effects of HIIT on cardiorespiratory fitness}

Cardiorespiratory fitness as measured using absolute $\mathrm{VO}_{2 \text { peak }}$ $(\mathrm{L} / \mathrm{min})$ and relative $\mathrm{VO}_{2 \text { peak }}(\mathrm{ml} / \mathrm{kg} / \mathrm{min})$ was analyzed using data from seven studies representing a total of 219 patients. As compared with baseline, there was a $4.75 \mathrm{ml} /$ $\mathrm{kg} / \mathrm{min}(95 \% \mathrm{CI} 2.94$ to $6.56, P<0.0001)$ (Fig. 3a; Table 2) or $0.35 \mathrm{~L} / \mathrm{min}$ (95\% CI 0.17 to $0.53, P=0.0001$ ) increase in $\mathrm{VO}_{2 \text { peak }}$ with HIIT (Fig. 4a; Table 3). In addition, there was a $4.12 \mathrm{ml} / \mathrm{kg} / \mathrm{min}$ (95\% CI 2.66 to $5.57, P<0.0001$ ) (Fig. 3b) or $0.24 \mathrm{~L} / \mathrm{min}$ (95\% CI 0.10 to $0.37, P=0.0005$ ) (Fig. $4 \mathrm{~b}$ ) increase in $\mathrm{VO}_{2 \text { peak }}$ with HIIT over control interventions. The random-effects model showed (Fig. 4c) a significant improvement in absolute $\mathrm{VO}_{2 \text { peak }}$ of $0.37 \mathrm{~L} / \mathrm{min}(95 \% \mathrm{CI}$ 0.28 to $0.45, P<0.0001)$ for patients in HIIT group versus those in the MICT group and there was a similar increase seen with respect to relative $\mathrm{VO}_{\text {2peak }}$ (MD: $3.37 \mathrm{ml} / \mathrm{kg} / \mathrm{min}$, 95\% CI 1.88 to $4.87, P<0.0001$ ) (Fig. 3c). However, there existed moderate heterogeneity in this analysis $\left(I^{2}=48 \%\right)$ and the results should be interpreted with caution (Table 4).

\section{Discussion}

The purpose of this study was to evaluate the effectiveness of HIIT on body composition, glycemic control, and cardiorespiratory fitness in patients with T2D; to observe the difference in such compared with MICT or non-exercise; and to provide information on an ideal time-efficient physical activity program. The principal finding of the current meta-analysis was that HIIT was more efficient than MICT in increasing $\mathrm{VO}_{2 \text { peak }}$ in T2D patients; they also found that reduction of BMI, body weight, and $\mathrm{HbA1c}(\%)$ was less conclusive because of low quality of the evidence.

Excess weight and obesity are important risk factors for the occurrence of T2D and contribute to the development of insulin resistance in obese individuals [31,32]. Even with a body weight that falls within the normal range, individuals with an abnormal BMI and waist circumference can also present with an increased risk of abnormal glucose metabolism [33]. Our work showed that HIIT improved body composition, reducing BMI significantly by $0.85 \mathrm{~kg} / \mathrm{m}^{2}$ and reducing body fat by $1.86 \%$. Notably, both body weight and BMI were significantly decreased compared with the 
Table 3 Effect of HIIT on body composition, glycemic control, lipid control, and cardiorespiratory fitness in patients with T2D

\begin{tabular}{|c|c|c|c|c|}
\hline \multicolumn{2}{|l|}{ Body composition } & \multirow{2}{*}{$\begin{array}{l}\text { Within groups } \\
11\end{array}$} & \multirow{2}{*}{$\begin{array}{l}\text { Compared to CON } \\
6\end{array}$} & \multirow{2}{*}{$\begin{array}{l}\text { Compared to MICT } \\
8\end{array}$} \\
\hline Body weight & $N$ & & & \\
\hline & $\mathrm{ES}(95 \% \mathrm{CI})$ & $\mathrm{MD}:-1.65[-4.76,1.46]$ & $\mathrm{MD}:-0.78[-2.36,0.80]$ & MD: $-1.22[-2.23,-0.18]$ \\
\hline & $I^{2}(\%)$ & 0 & 0 & 0 \\
\hline \multirow[t]{3}{*}{ BMI } & $N$ & 11 & 4 & 8 \\
\hline & $\mathrm{ES}(95 \% \mathrm{CI})$ & MD: $-0.85[-1.57,-0.12]$ & $\mathrm{MD}:-0.80[-1.86,0.27]$ & MD: $-0.40[-0.78,-0.02]$ \\
\hline & $I^{2}(\%)$ & 0 & 0 & 0 \\
\hline \multirow[t]{3}{*}{ Body fat (\%) } & $N$ & 6 & ND & 5 \\
\hline & $\mathrm{ES}(95 \% \mathrm{CI})$ & MD: $-1.86[-3.68,-0.04]$ & & MD: $-0.50[-1.18,0.19]$ \\
\hline & $I^{2}(\%)$ & 0 & & 0 \\
\hline \multirow[t]{3}{*}{ Waist circumference } & $N$ & 7 & ND & 6 \\
\hline & ES $(95 \% \mathrm{CI})$ & $\mathrm{MD}:-2.23[-5.00,0.55]$ & & MD: $-0.15[-1.21,0.91]$ \\
\hline & $I^{2}(\%)$ & 0 & & 0 \\
\hline \multicolumn{5}{|l|}{ Glycemic control } \\
\hline \multirow[t]{3}{*}{ HbA1c (\%) } & $N$ & 10 & 3 & 9 \\
\hline & $\mathrm{ES}(95 \% \mathrm{CI})$ & MD: $-0.29[-0.55,-0.04]$ & MD: $-0.39[-0.81,0.02]$ & MD: $-0.37[-0.55,-0.19]$ \\
\hline & $I^{2}(\%)$ & 0 & 0 & 0 \\
\hline \multirow[t]{3}{*}{ Fasting glucose } & $N$ & 9 & 5 & 8 \\
\hline & ES $(95 \% \mathrm{CI})$ & MD: $-0.41[-0.91,0.09]$ & SMD: $-0.31[-0.69,0.06]$ & MD: $0.10[-0.84,0.65]$ \\
\hline & $I^{2}(\%)$ & 0 & 0 & 0 \\
\hline \multirow[t]{3}{*}{ Fasting insulin } & $N$ & 6 & 5 & 4 \\
\hline & $\mathrm{ES}(95 \% \mathrm{CI})$ & SMD: $-0.46[-0.81,-0.11]$ & SMD: $-0.46[-0.91,0.02]$ & SMD: $-0.19[-0.58,0.20]$ \\
\hline & $I^{2}(\%)$ & 41 & 26 & 0 \\
\hline \multirow[t]{3}{*}{ HOMA-IR } & $N$ & 7 & 4 & 6 \\
\hline & $\mathrm{ES}(95 \% \mathrm{CI})$ & MD: $-0.43[-1.18,0.32]$ & MD: $-0.18[-0.79,0.42]$ & MD: $0.13[-0.10,0.36]$ \\
\hline & $I^{2}(\%)$ & 73 & 0 & 0 \\
\hline \multicolumn{5}{|l|}{ Lipid control } \\
\hline \multirow[t]{3}{*}{ Total cholesterol } & $N$ & 8 & 6 & 7 \\
\hline & $\mathrm{ES}(95 \% \mathrm{CI})$ & SMD: $-0.13[-0.42,0.15]$ & SMD: $0.02[-0.32,037]$ & MD: $-0.18[-0.44,0.07]$ \\
\hline & $I^{2}(\%)$ & 0 & 9 & 0 \\
\hline \multirow[t]{3}{*}{ HDL cholesterol } & $N$ & 11 & 5 & 9 \\
\hline & $\mathrm{ES}(95 \% \mathrm{CI})$ & SMD: $0.20[-0.07,0.48]$ & SMD: $0.60[-0.26,1.45]$ & MD: $-0.04[-0.10,0.02]$ \\
\hline & $I^{2}(\%)$ & 39 & 83 & 0 \\
\hline \multirow[t]{3}{*}{ LDL cholesterol } & $\mathrm{N}$ & 7 & 5 & 6 \\
\hline & $\mathrm{ES}(95 \% \mathrm{CI})$ & SMD: $-0.15[-0.44,0.13]$ & MD: $-0.60[-1.74,0.54]$ & MD: $-0.25[-0.46,-0.04]$ \\
\hline & $I^{2}(\%)$ & 0 & 52 & 0 \\
\hline \multicolumn{5}{|l|}{ Cardiorespiratory fitness } \\
\hline \multirow[t]{3}{*}{$\mathrm{VO}_{2 \text { peak }}(\mathrm{ml} / \mathrm{kg} / \mathrm{min})$} & $N$ & 7 & 2 & 7 \\
\hline & ES $(95 \% \mathrm{CI})$ & MD: $4.75[2.94,6.56]$ & MD: $4.12[2.66,5.57]$ & MD: $3.37[1.88,4.87]$ \\
\hline & $I^{2}(\%)$ & 0 & 0 & 48 \\
\hline \multirow[t]{3}{*}{$\mathrm{VO}_{2 \text { peak }}(\mathrm{L} / \mathrm{min})$} & $N$ & 5 & 2 & 6 \\
\hline & $\mathrm{ES}(95 \% \mathrm{CI})$ & MD: $0.35[0.17,0.53]$ & MD: $0.24[0.10,0.37]$ & MD: $0.37[0.28,0.45]$ \\
\hline & $I^{2}(\%)$ & 0 & 0 & 36 \\
\hline
\end{tabular}

$E S$ effect sizes, $C I$ confidence interval, $M D$ mean difference, $S M D$ standardized mean difference, $N D$ not enough data

MICT group, which suggests that HIIT may be more effective for improving body composition (even in the absence of changes in body fat and waist circumference) in individuals with T2D. The underlying mechanism of HIIT-induced body weight loss may be related to the consumption and release of fat from visceral fat stores. Maillard et al. [24] studied and compared the effects of HIIT and MICT on abdominal fat in postmenopausal women with T2D, and observed that only HIIT reduced the subcutaneous and visceral fat mass significantly following 16 weeks of training. Cassidy et al. 


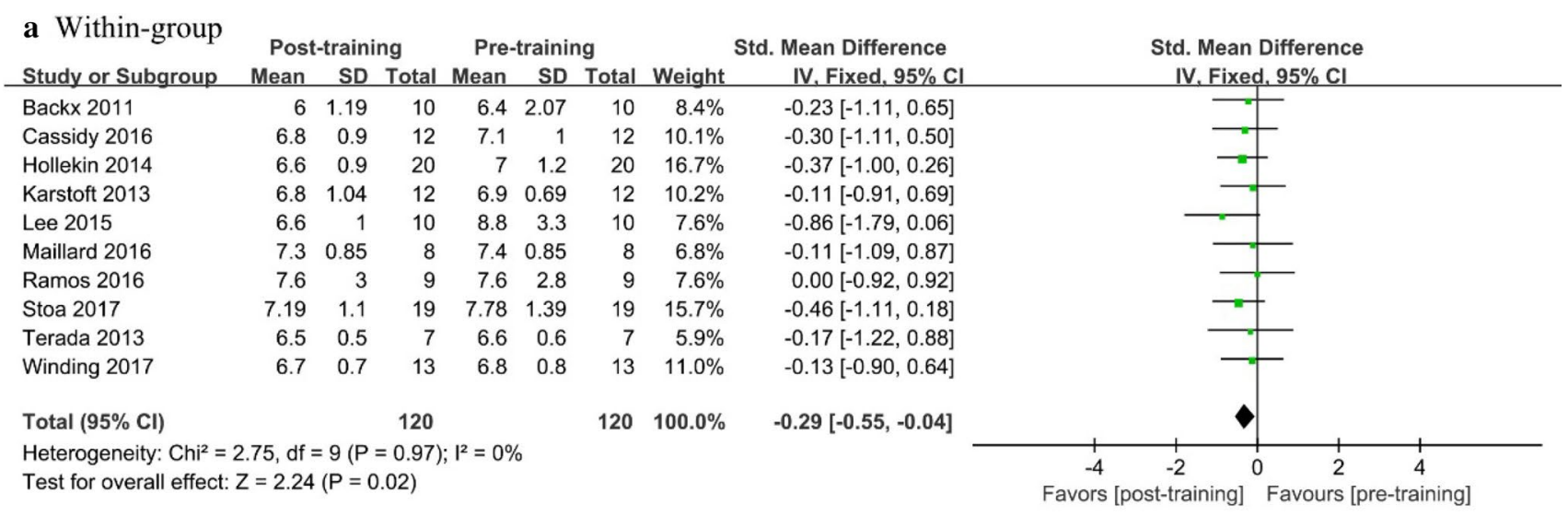

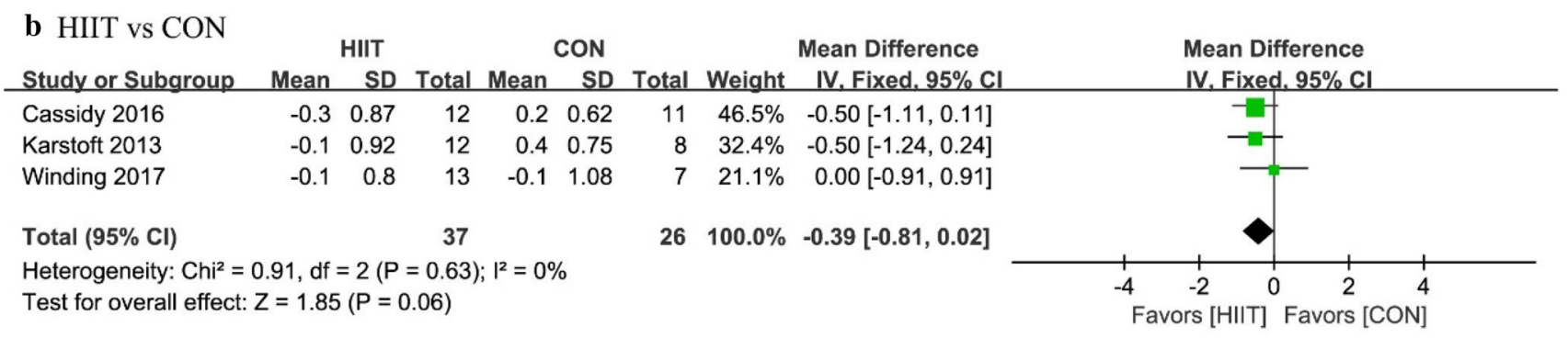

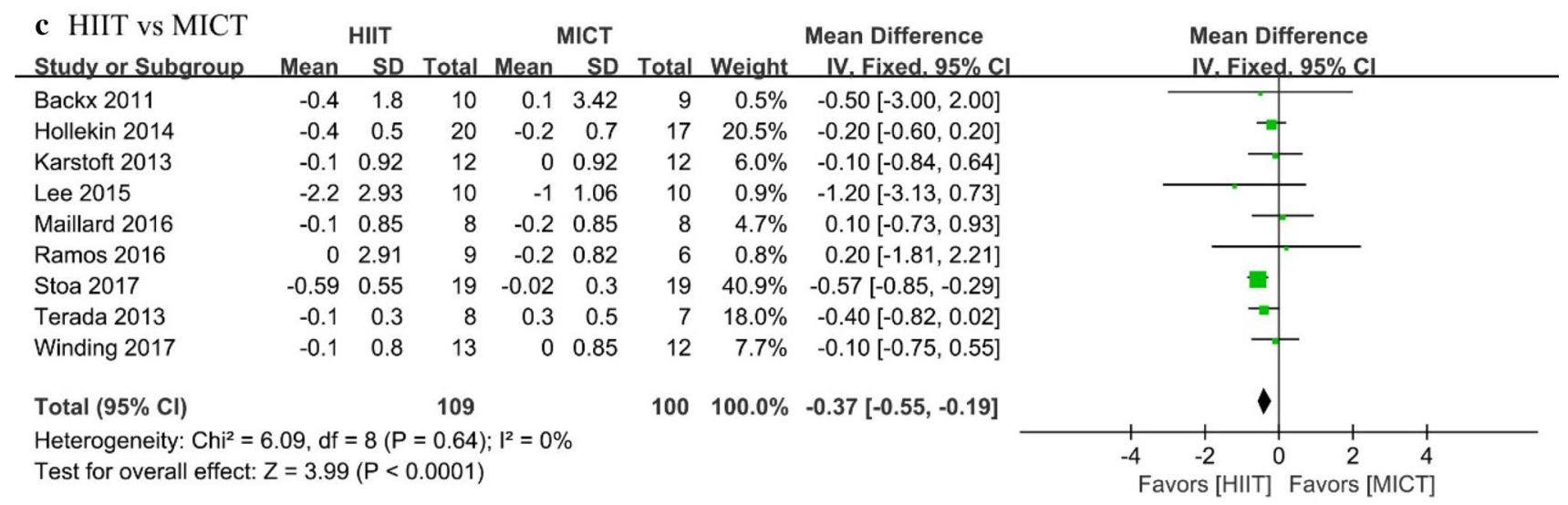

Fig. 2 Forest plot for change in of HbA1c (\%), a before and after (within-group) high-intensity interval training (HIIT), b between HIIT and control $(\mathrm{CON})$ intervention, and $\mathbf{c}$ between HIIT and moderate-intensity training (MICT)

[28] reported, in their randomized study, that there was a $39 \%$ relative reduction in liver fat following HIIT performance and observed that there was a significant correlation with changes in HbA1c and 2-h glucose. Moreover, Karstoft et al. [16] found that patients with T2D had greater oxygen consumption during HIIT training than did those who performed MICT, suggesting that this may be responsible for their greater weight loss. Recent studies have shown that the positive effects of exercise on body composition may be related to the improvement of glycemic control. For example, in a long-term randomized trial, Senechal et al. [34] found that changes in $\mathrm{HbAlc}$ were associated with changes in body weight, waist circumference, and trunk fat mass in individuals with T2D. Notably, however, although this review shows that HIIT has favorable effects on body fat reduction in individuals with $\mathrm{T} 2 \mathrm{D}$, the effects of HIIT on blood lipids were limited. Only LDL cholesterol showed significantly lower levels after HIIT than after MICT, while total cholesterol and HDL cholesterol did not. Thus, more studies are required to determine whether HIIT could be a successful training program for lipid control in T2D patients.

$\mathrm{HbA1c}$ is not only the most widely used indicator of glucose: it is also an important risk factor of cardiovascular disease in patients with T2D $[35,36]$. The previous studies have shown that if $\mathrm{HbA1c}$ levels are reduced by $1 \%$, the risk of microvascular complications is reduced by 


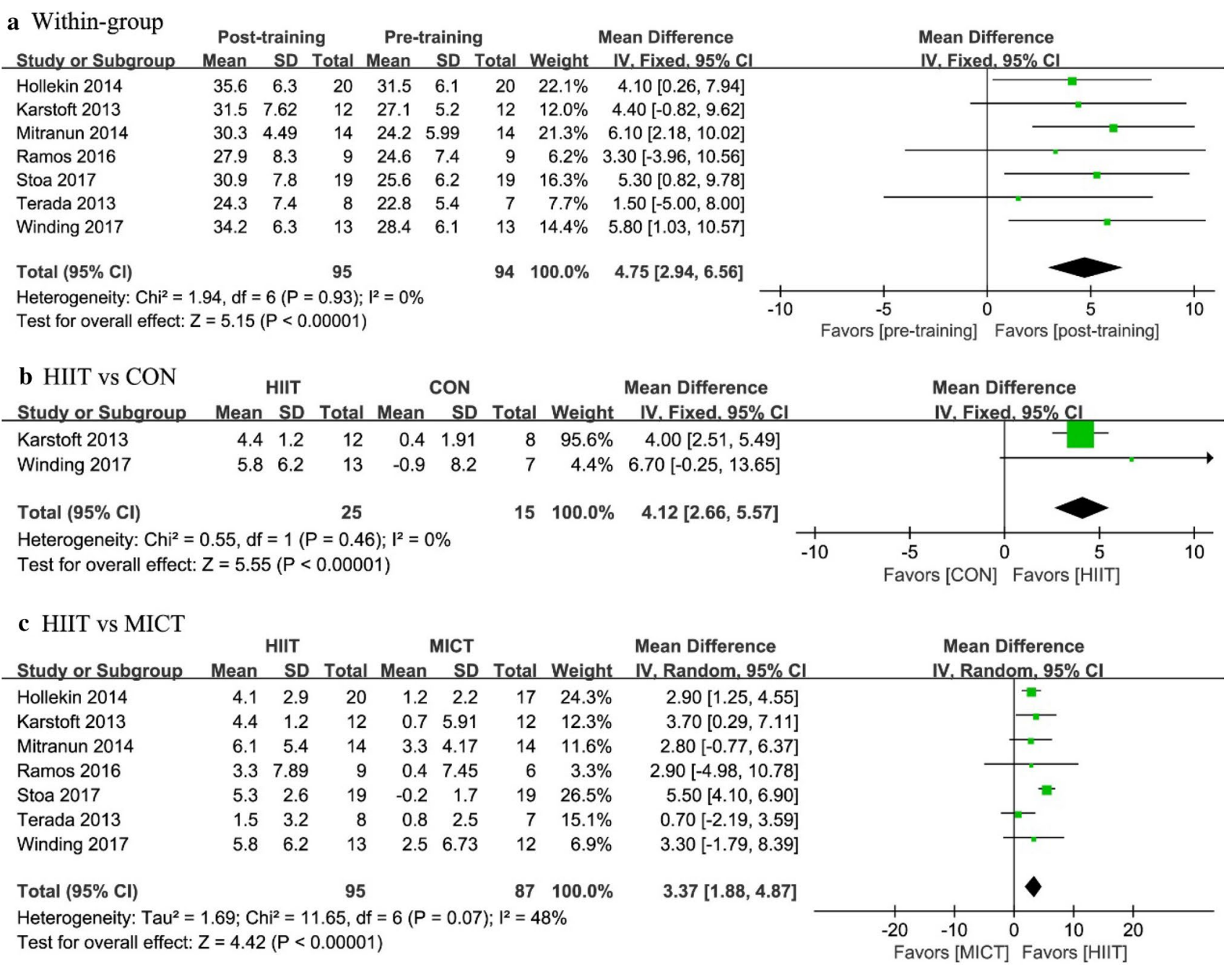

Fig. 3 Forest plot for change in $\mathrm{VO}_{2 \text { peak }}(\mathrm{ml} / \mathrm{kg} / \mathrm{min}$ ), a before and after (within-group) high-intensity interval training (HIIT), b between HIIT and control (CON) intervention, and $\mathbf{c}$ between HIIT and moderate-intensity training (MICT)

$37 \%$ and that of death related to diabetes can be reduced by $21 \%$ [35]. A recent meta-analysis has shown that an increase of $100 \mathrm{~min}$ in physical activity per week was associated with an average change of $-0.16 \%$ of $\mathrm{HbA} 1 \mathrm{c}$ in individuals with T2D and pre-diabetes subjects [37]. In our meta-analysis, HbA1c (\%) was found to be lower after HIIT than at baseline (SMD: $-0.29,95 \% \mathrm{CI}-0.55$ to - 0.04). Similar to our findings, a recent meta-analysis of RCTs by Grace et al. identified the positive effects of aerobic exercise in reducing $\mathrm{HbA} 1 \mathrm{c}$ levels over with controls [11]. HIIT showed a $0.37 \%$ greater reduction of $\mathrm{HbA} 1 \mathrm{c}$ than MICT, which means that HIIT may have additional benefits on glycemic control. This is inconsistent with the findings of a meta-analysis conducted by Jelleyman et al. [18], which found that, while HIIT can reduce the levels of $\mathrm{HbA} 1 \mathrm{c}$ in patients with diabetes and metabolic syndrome, there is no significant difference in reduction versus with continuous training. Furthermore, in a previous review with a meta-analysis, it was concluded that exercise intensity was a better predictor of weight MD in $\mathrm{HbA} 1 \mathrm{c}$ than exercise volume in T2D patients [38]. Unfortunately, we noted no difference in fasting glucose, fasting insulin, or insulin resistance changes in patients following HIIT as compared with the CON and MICT groups, even though the previous studies have shown that the effects of aerobic training on insulin intensity are more closely influenced by high-exercise intensity than by low- or moderate-intensity exercise [39]. The inconsistent results could partly be explained by the difference among methods used to measure insulin sensitivity, as well as the difference in the baseline of glycemic control. Further research would need to include data on the HIIT intervention program (e.g., training intensity, duration of interval time, frequency of training, and total duration) and the characteristics of patients (especially with respect to age, duration 


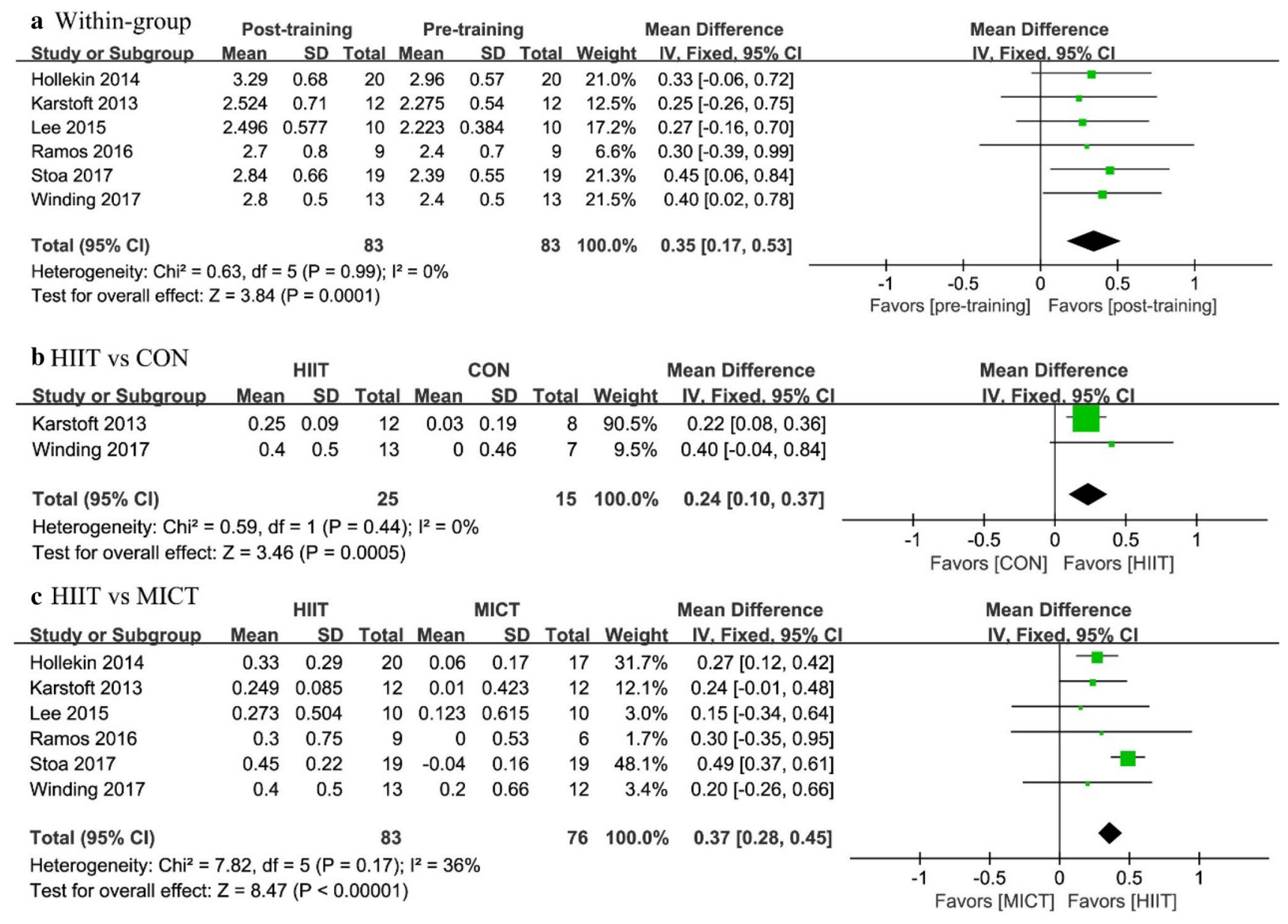

Fig. 4 Forest plot for change in $\mathrm{VO}_{2 \text { peak }}(\mathrm{L} / \mathrm{min}$ ), a before and after (within-group) high-intensity interval training (HIIT), b between HIIT and control $(\mathrm{CON})$ intervention, and $\mathbf{c}$ between HIIT and moderate-intensity training (MICT)

of diabetes, and the baseline glycemic control), which all impact trial results.

Both $\mathrm{VO}_{2 \text { peak }}$ and $\mathrm{HbAlc}$ are important predictors of cardiovascular events in T2D patients [35], and the previous studies have shown that low cardiorespiratory fitness was associated with an increased risk for impaired glycemic control [40, 41]. Aerobic exercise training represents an effective means to improve $\mathrm{VO}_{2 \text { peak }}$ and $\mathrm{HbAlc}$, and a previous meta-analysis has revealed that aerobic exercise intensity is the primary stimulus for improved $\mathrm{VO}_{2 \text { peak }}$ in people with T2D [11]. Our study further compared the difference between HIIT and MICT in increasing peak $\mathrm{VO}_{2}$ and found that the improvement of $3.37 \mathrm{ml} / \mathrm{kg} / \mathrm{min}$ in relative $\mathrm{VO}_{2 \text { peak }}$ and $0.37 \mathrm{~L} / \mathrm{min}$ in absolute $\mathrm{VO}_{2 \text { peak }}$ following HIIT is superior to those seen with MICT. Our findings are similarly to those from other recent studies. A meta-analysis focused mainly on cardiac patients by Xie et al. [42] showed that HIIT is more effective than continuous training in improving $\mathrm{VO}_{2 \text { peak }}$ [MD: $1.76 \mathrm{ml} / \mathrm{kg} / \mathrm{min}, 95 \%$ CI 1.06 to $2.46 \mathrm{ml} /$ $\mathrm{kg} / \mathrm{min}$ ]. Another systemic analysis analyzing 65 studies by
Batacan et al. [43] revealed that HIIT yielded a significant increase in $\mathrm{VO}_{2 \text { peak }}$ by a large amount in normal-weight populations and a medium effect in overweight/obese populations, with an aggregate improvement of 3.8 and $4.43 \mathrm{ml} /$ $\mathrm{kg} / \mathrm{min}$, respectively. A more recent meta-analysis including 594 coronary artery disease patients by Gomes-Noto et al. [44] reported that a higher improvement in $\mathrm{VO}_{2 \text { peak }}$ (MD: $1.3 \mathrm{ml} / \mathrm{kg} / \mathrm{min}, 95 \%$ CI 0.6 to $1.9 \mathrm{ml} / \mathrm{kg} / \mathrm{min}$ ) was seen with HIIT versus with MICT. The underlying physiological mechanisms of HIIT that improve peak $\mathrm{VO}_{2}$ could not be ascertained from the present study, but may involve a combination of central and peripheral adaptations, including an increase in cardiac output, an improvement in vascular/endothelial function, and increased muscle oxidation, which together promote the enhanced availability, extraction, and use of oxygen during exercise [45, 46]. Revdal et al. [47] studied the impact of HIIT on cardiac structure and function in T2D patients, and observed a $12 \%$ relative increase in left-ventricular wall mass and increased enddiastolic blood volume, thus demonstrating improvements 
Table 4 Summary of GRADE's approach to rating quality of evidence

\begin{tabular}{|c|c|c|c|c|c|c|c|c|}
\hline \multirow[t]{2}{*}{ Outcomes } & \multicolumn{8}{|c|}{ Quality assessment } \\
\hline & Comparison & $\begin{array}{l}\text { Participants } \\
\text { (studies) follow } \\
\text { up }\end{array}$ & Risk of bias & Inconsistency & Indirectness & Imprecision & Publication bias & $\begin{array}{l}\text { Overall quality of } \\
\text { evidence }\end{array}$ \\
\hline \multirow[t]{2}{*}{ Body weight } & MICT & $\begin{array}{l}185 \text { (eight stud- } \\
\text { ies) }\end{array}$ & None & None & Serious & Serious & Undetected & $\begin{array}{c}\oplus \oplus \Theta \Theta \text { Low due } \\
\text { to indirectness } \\
\text { and imprecision }\end{array}$ \\
\hline & $\mathrm{CON}$ & 136 (six studies) & None & None & Serious & Serious & Undetected & $\begin{array}{c}\oplus \oplus \Theta \Theta \text { Low due } \\
\text { to indirectness } \\
\text { and imprecision }\end{array}$ \\
\hline \multirow[t]{2}{*}{ BMI } & MICT & $\begin{array}{l}207 \text { (eight stud- } \\
\text { ies) }\end{array}$ & None & None & Serious & Serious & Undetected & $\begin{array}{c}\oplus \oplus \Theta \Theta \text { Low due } \\
\text { to indirectness } \\
\text { and imprecision }\end{array}$ \\
\hline & $\mathrm{CON}$ & $\begin{array}{l}72 \text { (three stud- } \\
\text { ies) }\end{array}$ & None & None & Serious & Serious & Undetected & $\begin{array}{c}\oplus \oplus \Theta \Theta \text { Low due } \\
\text { to indirectness } \\
\text { and imprecision }\end{array}$ \\
\hline \multirow[t]{2}{*}{ Body fat (\%) } & MICT & $\begin{array}{l}138 \text { (five stud- } \\
\text { ies) }\end{array}$ & Serious & Very serious & None & Serious & Undetected & $\begin{array}{c}\oplus \Theta \Theta \Theta \text { Very low } \\
\text { due to risk of } \\
\text { bias, incon- } \\
\text { sistency and } \\
\text { imprecision }\end{array}$ \\
\hline & $\mathrm{CON}$ & ND & ND & ND & ND & ND & ND & ND \\
\hline \multirow[t]{2}{*}{$\begin{array}{l}\text { Waist circum- } \\
\text { ference }\end{array}$} & MICT & 140 (six studies) & None & Serious & None & Serious & Undetected & $\begin{array}{r}\oplus \oplus \Theta \Theta \text { Low due } \\
\text { to inconsistency } \\
\text { and imprecision }\end{array}$ \\
\hline & $\mathrm{CON}$ & ND & ND & ND & ND & ND & ND & ND \\
\hline \multirow[t]{2}{*}{ HbA1c $(\%)$} & MICT & $\begin{array}{l}209 \text { (nine stud- } \\
\text { ies) }\end{array}$ & None & Serious & None & Serious & Undetected & $\begin{array}{l}\oplus \oplus \Theta \Theta \text { Low due } \\
\text { to inconsist- } \\
\text { ency, impreci- } \\
\text { sion }\end{array}$ \\
\hline & $\mathrm{CON}$ & $\begin{array}{l}63 \text { (three stud- } \\
\text { ies) }\end{array}$ & None & Serious & None & Serious & Undetected & $\begin{array}{r}\oplus \oplus \Theta \Theta \text { Low due } \\
\text { to inconsistency } \\
\text { and imprecision }\end{array}$ \\
\hline \multirow[t]{2}{*}{ Fasting glucose } & MICT & $\begin{array}{l}162 \text { (eight stud- } \\
\text { ies) }\end{array}$ & None & Serious & None & Serious & Undetected & $\begin{array}{r}\oplus \oplus \Theta \Theta \text { Low due } \\
\text { to inconsistency } \\
\text { and imprecision }\end{array}$ \\
\hline & $\mathrm{CON}$ & $\begin{array}{l}114 \text { (five stud- } \\
\text { ies) }\end{array}$ & None & Serious & None & Serious & Undetected & $\begin{array}{r}\oplus \oplus \Theta \Theta \text { Low due } \\
\text { to inconsistency } \\
\text { and imprecision }\end{array}$ \\
\hline \multirow[t]{2}{*}{ Fasting insulin } & MICT & $\begin{array}{l}103 \text { (five stud- } \\
\text { ies) }\end{array}$ & None & Serious & None & Serious & Undetected & $\begin{array}{r}\oplus \oplus \Theta \Theta \text { Low due } \\
\text { to inconsistency } \\
\text { and imprecision }\end{array}$ \\
\hline & $\mathrm{CON}$ & 85 (four studies) & None & Serious & None & Serious & Undetected & $\begin{array}{r}\oplus \oplus \Theta \Theta \text { Low due } \\
\text { to inconsistency } \\
\text { and imprecision }\end{array}$ \\
\hline \multirow[t]{2}{*}{ HOMA-IR } & MICT & $\begin{array}{l}182 \text { (seven stud- } \\
\text { ies) }\end{array}$ & None & Very serious & None & Serious & Undetected & $\begin{array}{l}\oplus \Theta \Theta \Theta \text { Very low } \\
\text { due to incon- } \\
\text { sistency and } \\
\text { imprecision }\end{array}$ \\
\hline & $\mathrm{CON}$ & 99 (four studies) & None & Very serious & None & Serious & Undetected & $\begin{array}{l}\oplus \Theta \Theta \Theta \text { Very low } \\
\text { due to incon- } \\
\text { sistency and } \\
\text { imprecision }\end{array}$ \\
\hline
\end{tabular}


Table 4 (continued)

\begin{tabular}{|c|c|c|c|c|c|c|c|c|}
\hline \multirow[t]{2}{*}{ Outcomes } & \multicolumn{8}{|c|}{ Quality assessment } \\
\hline & Comparison & $\begin{array}{l}\text { Participants } \\
\text { (studies) follow } \\
\text { up }\end{array}$ & Risk of bias & Inconsistency & Indirectness & Imprecision & Publication bias & $\begin{array}{l}\text { Overall quality of } \\
\text { evidence }\end{array}$ \\
\hline \multirow[t]{2}{*}{$\begin{array}{l}\text { Total choles- } \\
\text { terol }\end{array}$} & MICT & $\begin{array}{l}165 \text { (seven stud- } \\
\text { ies) }\end{array}$ & None & Serious & None & Serious & Undetected & $\begin{array}{r}\oplus \oplus \Theta \Theta \text { Low due } \\
\text { to inconsistency } \\
\text { and imprecision }\end{array}$ \\
\hline & $\mathrm{CON}$ & 137 (six studies) & None & Serious & None & Serious & Undetected & $\begin{array}{r}\oplus \oplus \Theta \Theta \text { Low due } \\
\text { to inconsistency } \\
\text { and imprecision }\end{array}$ \\
\hline \multirow[t]{2}{*}{$\begin{array}{l}\text { HDL choles- } \\
\text { terol }\end{array}$} & MICT & $\begin{array}{l}204 \text { (nine stud- } \\
\text { ies) }\end{array}$ & None & Serious & None & Serious & $\begin{array}{l}\text { Reporting bias } \\
\text { strongly sus- } \\
\text { pected }\end{array}$ & $\begin{array}{l}\oplus \Theta \Theta \Theta \text { Very } \\
\text { low due to } \\
\text { inconsistency, } \\
\text { imprecision and } \\
\text { publication bias }\end{array}$ \\
\hline & $\mathrm{CON}$ & $\begin{array}{l}114 \text { (five stud- } \\
\text { ies) }\end{array}$ & None & Serious & None & Serious & $\begin{array}{l}\text { Reporting bias } \\
\text { strongly sus- } \\
\text { pected }\end{array}$ & $\begin{array}{l}\oplus \Theta \Theta \Theta \text { Very } \\
\text { low due to } \\
\text { inconsistency, } \\
\text { imprecision and } \\
\text { publication bias }\end{array}$ \\
\hline \multirow[t]{2}{*}{ LDL } & MICT & 150 (six studies) & None & Serious & None & Serious & $\begin{array}{l}\text { Reporting bias } \\
\text { strongly sus- } \\
\text { pected }\end{array}$ & $\begin{array}{l}\oplus \Theta \Theta \Theta \text { Very } \\
\text { low due to } \\
\text { inconsistency, } \\
\text { imprecision and } \\
\text { publication bias }\end{array}$ \\
\hline & $\mathrm{CON}$ & $\begin{array}{l}114 \text { (five stud- } \\
\text { ies) }\end{array}$ & None & Very serious & None & Serious & None & $\begin{array}{l}\oplus \Theta \Theta \Theta \text { Very low } \\
\text { due to incon- } \\
\text { sistency and } \\
\text { imprecision }\end{array}$ \\
\hline \multirow[t]{2}{*}{$\begin{array}{l}\text { VO2peak (L/ } \\
\text { min) }\end{array}$} & MICT & 159 (six studies) & None & Serious & None & Serious & Undetected & $\begin{array}{l}\oplus \oplus \oplus \Theta \text { Moder- } \\
\text { ate due to } \\
\text { inconsistency, } \\
\text { imprecision and } \\
\text { large effect }\end{array}$ \\
\hline & $\mathrm{CON}$ & 40 (two studies) & None & Serious & None & Serious & Undetected & $\begin{array}{r}\oplus \oplus \Theta \Theta \text { Low due } \\
\text { to inconsistency } \\
\text { and imprecision }\end{array}$ \\
\hline \multirow[t]{2}{*}{$\begin{array}{l}\text { VO2peak (ml/ } \\
\mathrm{kg} / \mathrm{min})\end{array}$} & MICT & $\begin{array}{l}182 \text { (seven stud- } \\
\text { ies) }\end{array}$ & Serious & Serious & None & Serious & Undetected & $\begin{array}{l}\oplus \oplus \oplus \Theta \text { Moder- } \\
\text { ate due to } \\
\text { inconsistency, } \\
\text { imprecision and } \\
\text { large effect }\end{array}$ \\
\hline & $\mathrm{CON}$ & 40 (two studies) & None & Serious & None & Serious & Undetected & $\begin{array}{r}\oplus \oplus \Theta \Theta \text { Low due } \\
\text { to inconsistency } \\
\text { and imprecision }\end{array}$ \\
\hline
\end{tabular}

in systolic function, as indicated by raised stroke volume and left-ventricular ejection fraction. A similar finding was found by Hollekin et al. [22], who observed that both MICT and HIIT groups showed improved diastolic function at rest, but that the HIIT group showed greater improvement than did the MICT group. Moreover, Little et al. [48] found that people with T2D who performed six sessions of low-volume HIIT at an intensity of $90 \%$ of the maximal heart rate with 60 -s rest over 2 weeks experienced an increase in maximal activity of citrate synthesis and skeletal muscle mitochondrial protein content, suggesting that the increases in skeletal muscle mitochondrial content and function following low-volume HIIT may be contributing factors to improved $\mathrm{VO}_{2 \text { peak }}$. 


\section{Strengths and limitations}

Our meta-analysis of randomized trials has several strengths. First, to our knowledge, this is the first existing systematic review to compare the effects of HIIT and MICT or nonexercise on glycemic control (e.g., HbAlc, insulin, and fasting glucose); body composition (e.g., body weight, body fat, BMI, and waist circumference); and cardiorespiratory fitness (e.g., $\mathrm{VO}_{2 \text { peak }}$ ) among people with T2D. Second, this systematic review involved a large number of literature searches by two reviewers who independently screened studies, assessed their quality, and extracted data to decrease publishing bias and increase credibility.

However, some limitations were still present in our evaluation. First, there are some inconsistencies among the included studies with respect to HIIT protocols and MICT protocols, which may have affected the results obtained with respect to the intervention and control groups. Second, considering the low quality of evidence, these results may have some limitations in guiding clinical applications. Third, an important limitation is that most of the included studies reported the pre- and post-intervention parameters but not the differences between the baselines. Therefore, considering the different baseline values that may be present between the intervention and control groups in some studies, we used equations to calculate the mean difference whenever it was not reported to address the discrepancy of the baseline in each group, and this could have resulted in a bias. Fourth, the results of this meta-analysis are limited by the lack of high-quality studies and the small number of patients in each included study. Only four of the included studies clearly indicated random sequence generation, while three studies reported allocation concealment, and five studies blinded participants in their experimental procedures.

\section{Conclusions}

In conclusion, we here demonstrated that HIT is an effective strategy for improving cardiorespiratory fitness in patients with T2D, preferable to MICT. Results related to other parameters associated with the prognosis of T2D, such as HbA1c, body weight, and BMI, were not conclusive. This review can still provide some suggestions for the clinical application of HIIT in T2D patients. Future studies should investigate the effects of HIIT in T2D patients through multicenter RCTs with large sample sizes over the long term.

Acknowledgements We would like to thank LetPub (http://www.letpu b.com) for providing linguistic assistance during the preparation of this manuscript.
Author contributions Jing-xin Liu contributed to study conception and design, drafting the submitted article, and critically revising the draft for important intellectual content. Lin Zhu revised the draft critically for important intellectual content and gave final approval of the version for publication. Pei-jun Li, Ning Li, and Yan-bing Xu contributed to acquisition, analysis, and interpretation the data. All authors contributed at all stages of this study, gave final approval of the version for publication, and agree to be accountable for all aspects of the work.

Funding This work was supported by the National Planning Office of Philosophy and Social Science of China (No. 18BTY075), the research projects of the Social Science and Humanity on Young Fund of the Ministry of education of China (No. 13yjc890050), the research projects of the Department of Education of Guangdong Province (No. 2015KTSCX079), the research projects of the Department of Science and Technology of Guangdong Province (No. 2015A020219010 and No. 2014A020220010).

\section{Compliance with ethical standards}

Conflict of interest The authors declare that there is no conflict of interest regarding the publication of this paper.

Statement of human and animal rights This review does not contain any experiments involving human participants or animals performed by any of authors.

Informed consent For this review, formal consent forms were not required.

Open Access This article is distributed under the terms of the Creative Commons Attribution 4.0 International License (http://creativeco mmons.org/licenses/by/4.0/), which permits unrestricted use, distribution, and reproduction in any medium, provided you give appropriate credit to the original author(s) and the source, provide a link to the Creative Commons license, and indicate if changes were made.

\section{References}

1. WHO (2016) Global Report on Diabetes. WHO. http://www.who. int/diabetes/publications/grd-2016/en/. Accessed 6 April 2016

2. Whiting DR, Guariguata L, Weil C et al (2011) IDF diabetes atlas: global estimates of the prevalence of diabetes for 2011 and 2030. Diabetes Res Clin Pract 94:311-321. https://doi.org/10.1016/j. diabres.2011.10.029

3. Johansen MY, MacDonald CS, Hansen KB et al (2017) Effect of an intensive lifestyle intervention on glycemic control in patients with type 2 diabetes: a randomized clinical trial. JAMA 318:637646. https://doi.org/10.1001/jama.2017.10169

4. Ribisl PM, Gaussoin SA, Lang W et al (2012) Lifestyle intervention improves heart rate recovery from exercise in adults with type 2 diabetes: results from the Look AHEAD study. J Obes 2012:309196. https://doi.org/10.1155/2012/309196

5. Colberg SR, Sigal RJ, Fernhall B et al (2010) Exercise and type 2 diabetes: the American College of Sports Medicine and the American Diabetes Association: joint position statement executive summary. Diabetes Care 33:2692-2696. https://doi.org/10.2337/ dc10-1548

6. Anderson JE, Greene MA, Griffin JW et al (2012) Diabetes and employment. Diabetes Care 35:S94-S98. https://doi.org/10.2337/ dc12-s094 
7. Sigal RJ, Kenny GP, Boule NG et al (2007) Effects of aerobic training, resistance training, or both on glycemic control in type 2 diabetes: a randomized trial. Ann Intern Med 147:357-369. https ://doi.org/10.7326/0003-4819-147-6-200709180-00005

8. Church TS, Blair SN, Cocreham S et al (2010) Effects of aerobic and resistance training on hemoglobin A1c levels in patients with type 2 diabetes: a randomized controlled trial. JAMA 304:22532262. https://doi.org/10.1001/jama.2010.1710

9. Jorge ML, de Oliveira VN, Resende NM et al (2011) The effects of aerobic, resistance, and combined exercise on metabolic control, inflammatory markers, adipocytokines, and muscle insulin signaling in patients with type 2 diabetes mellitus. Metabolism 60:1244-1252. https://doi.org/10.1016/j.metabol.2011.01.006

10. Motahari-Tabari N, Ahmad Shirvani M, Shirzad EAM et al (2014) The effect of 8 weeks aerobic exercise on insulin resistance in type 2 diabetes: a randomized clinical trial. Global J Health Sci 7:115-121. https://doi.org/10.5539/gjhs.v7n1p115

11. Grace A, Chan E, Giallauria F et al (2017) Clinical outcomes and glycaemic responses to different aerobic exercise training intensities in type II diabetes: a systematic review and meta-analysis. Cardiovasc Diabetol 16:37. https://doi.org/10.1186/s1293 3-017-0518-6

12. Ellingsen O, Halle M, Conraads V et al (2017) High-intensity interval training in patients with heart failure with reduced ejection fraction. Circulation 135:839-849. https://doi.org/10.1161/ circulationaha.116.022924

13. Wisloff U, Stoylen A, Loennechen JP et al (2007) Superior cardiovascular effect of aerobic interval training versus moderate continuous training in heart failure patients: a randomized study. Circulation 115:3086-3094. https://doi.org/10.1161/circulatio naha.106.675041

14. Phillips BE, Kelly BM, Lilja M et al (2017) A practical and time-efficient high-intensity interval training program modifies cardio-metabolic risk factors in adults with risk factors for type II diabetes. Front Endocrinol 8:229. https://doi.org/10.3389/fendo .2017 .00229

15. Støa EM, Meling S, Nyhus LK et al (2017) High-intensity aerobic interval training improves aerobic fitness and $\mathrm{HbA} 1 \mathrm{c}$ among persons diagnosed with type 2 diabetes. Eur J Appl Physiol 117:455467. https://doi.org/10.1007/s00421-017-3540-1

16. Karstoft K, Winding K, Knudsen SH et al (2013) The effects of free-living interval-walking training on glycemic control, body composition, and physical fitness in type 2 diabetic patients: a randomized, controlled trial. Diabetes Care 36:228-236. https:// doi.org/10.2337/dc12-0658

17. Mitranun W, Deerochanawong C, Tanaka H et al (2014) Continuous vs interval training on glycemic control and macro- and microvascular reactivity in type 2 diabetic patients. Scand J Med Sci Sports 24:e69-e76. https://doi.org/10.1111/sms.12112

18. Jelleyman C, Yates T, O'Donovan G et al (2015) The effects of high-intensity interval training on glucose regulation and insulin resistance: a meta-analysis. Obes Rev 16:942-961. https://doi. org/10.1111/obr.12317

19. Higgins JP, Altman DG, Gotzsche PC et al (2011) The Cochrane Collaboration's tool for assessing risk of bias in randomised trials. BMJ 343:d5928. https://doi.org/10.1136/bmj.d5928

20. Balshem H, Helfand M, Schunemann HJ et al (2011) GRADE guidelines: 3. Rating the quality of evidence. J Clin Epidemiol 64:401-406. https://doi.org/10.1016/j.jclinepi.2010.07.015

21. Alvarez C, Ramirez-Campillo R, Martinez-Salazar C et al (2016) Low-volume high-intensity interval training as a therapy for type 2 diabetes. Int J Sports Med 37:723-729. https://doi. org/10.1055/s-0042-104935

22. Hollekim-Strand SM, Bjorgaas MR, Albrektsen G et al (2014) High-intensity interval exercise effectively improves cardiac function in patients with type 2 diabetes mellitus and diastolic dysfunction: a randomized controlled trial. J Am Coll Cardiol 64:1758-1760. https://doi.org/10.1016/j.jacc.2014.07.971

23. Lee SS, Yoo JH, So YS (2015) Effect of the low- versus highintensity exercise training on endoplasmic reticulum stress and GLP-1 in adolescents with type 2 diabetes mellitus. J Phys Ther Sci 27:3063-3068. https://doi.org/10.1589/jpts.27.3063

24. Maillard F, Rousset S, Pereira B et al (2016) High-intensity interval training reduces abdominal fat mass in postmenopausal women with type 2 diabetes. Diabetes Metab 42:433-441. https ://doi.org/10.1016/j.diabet.2016.07.031

25. Ramos JS, Dalleck LC, Borrani F et al (2016) The effect of different volumes of high-intensity interval training on proinsulin in participants with the metabolic syndrome: a randomised trial. Diabetologia 59:2308-2320. https://doi.org/10.1007/s0012 5-016-4064-7

26. Terada T, Friesen A, Chahal BS et al (2013) Feasibility and preliminary efficacy of high intensity interval training in type 2 diabetes. Diabetes Res Clin Pract 99:120-129. https://doi.org/10.1016/j. diabres.2012.10.019

27. Backx K, McCann A, Wasley D et al (2011) The effect of a supported exercise programme in patients with newly diagnosed Type 2 diabetes: a pilot study. J Sports Sci 29:579-586. https://doi. org/10.1080/02640414.2010.544666

28. Cassidy S, Thoma C, Hallsworth K et al (2016) High intensity intermittent exercise improves cardiac structure and function and reduces liver fat in patients with type 2 diabetes: a randomised controlled trial. Diabetologia 59:56-66. https://doi.org/10.1007/ s00125-015-3741-2

29. Bellia A, Iellamo F, De Carli E et al (2017) Exercise individualized by TRIMPi method reduces arterial stiffness in early onset type 2 diabetic patients: a randomized controlled trial with aerobic interval training. Int J Cardiol 248:314-319. https://doi. org/10.1016/j.ijcard.2017.06.065

30. Winding KM, Munch GW, Iepsen UW et al (2018) The effect on glycaemic control of low-volume high-intensity interval training versus endurance training in individuals with type 2 diabetes. Diabetes 20:1131-1139. https://doi.org/10.1111/dom.13198

31. Kahn SE, Hull RL, Utzschneider KM (2006) Mechanisms linking obesity to insulin resistance and type 2 diabetes. Nature 444:840 846. https://doi.org/10.1038/nature05482

32. Heianza Y, Kato K, Kodama S et al (2015) Risk of the development of Type 2 diabetes in relation to overall obesity, abdominal obesity and the clustering of metabolic abnormalities in Japanese individuals: does metabolically healthy overweight really exist? The Niigata Wellness Study. Diabetic Med 32:665-672. https:// doi.org/10.1111/dme.12646

33. Li S, Xiao J, Ji L et al (2014) BMI and waist circumference are associated with impaired glucose metabolism and type 2 diabetes in normal weight Chinese adults. J Diabetes Complicat 28:470476. https://doi.org/10.1016/j.jdiacomp.2014.03.015

34. Senechal M, Swift DL, Johannsen NM et al. (2013) Changes in body fat distribution and fitness are associated with changes in hemoglobin A1c after 9 months of exercise training: results from the HART-D study. Diabetes Care 36:2843-2849. https://doi. org/10.2337/dc12-2428

35. Stratton IM, Adler AI, Neil HA et al (2000) Association of glycaemia with macrovascular and microvascular complications of type 2 diabetes (UKPDS 35): prospective observational study. BMJ 321:405-412. https://doi.org/10.1136/bmj.321.7258.405

36. Woerle HJ, Neumann C, Zschau S et al (2007) Impact of fasting and postprandial glycemia on overall glycemic control in type 2 diabetes Importance of postprandial glycemia to achieve target HbA1c levels. Diabetes Res Clin Pract 77:280-285. https://doi. org/10.1016/j.diabres.2006.11.011

37. Boniol M, Dragomir M (2017) Physical activity and change in fasting glucose and HbA1c: a quantitative meta-analysis 
of randomized trials. Acta Diabetol 54:983-991. https://doi. org/10.1007/s00592-017-1037-3

38. Boule NG, Kenny GP, Haddad E et al (2003) Meta-analysis of the effect of structured exercise training on cardiorespiratory fitness in Type 2 diabetes mellitus. Diabetologia 46:1071-1081. https:// doi.org/10.1007/s00125-003-1160-2

39. DiPietro L, Dziura J, Yeckel CW et al (2006) Exercise and improved insulin sensitivity in older women: evidence of the enduring benefits of higher intensity training. J Appl Physiol (Bethesda Md 1985) 100:142-149. https://doi.org/10.1152/jappl physiol.00474.2005

40. Nojima H, Yoneda M, Watanabe H et al (2017) Association between aerobic capacity and the improvement in glycemic control after the exercise training in type 2 diabetes. Diabetol Metab Syndr 9:63. https://doi.org/10.1186/s13098-017-0262-9

41. Wei M, Gibbons LW, Mitchell TL et al (1999) The association between cardiorespiratory fitness and impaired fasting glucose and type 2 diabetes mellitus in men. Ann Intern Med 130:89-96. https://doi.org/10.7326/0003-4819-130-2-199901190-00002

42. Xie B, Yan X, Cai X (2017) Effects of high-intensity interval training on aerobic capacity in cardiac patients. Syst Rev Meta Anal. https://doi.org/10.1155/2017/5420840

43. Batacan RB, Duncan MJ, Dalbo VJ et al (2017) Effects of highintensity interval training on cardiometabolic health: a systematic review and meta-analysis of intervention studies. $\mathrm{Br} J$ Sports Med 51:494-503. https://doi.org/10.1136/bjsports-2015-095841
44. Gomes-Neto M, Duraes AR, Reis H et al (2017) High-intensity interval training versus moderate-intensity continuous training on exercise capacity and quality of life in patients with coronary artery disease: A systematic review and meta-analysis. Eur J Prevent Cardiol 24:1696-1707. https://doi.org/10.1177/2047487317 728370

45. Ramos JS, Dalleck LC, Tjonna AE et al (2015) The impact of high-intensity interval training versus moderate-intensity continuous training on vascular function: a systematic review and meta-analysis. Sports Med (Auckland NZ) 45:679-692. https:// doi.org/10.1007/s40279-015-0321-z

46. Moholdt T, Aamot IL, Granoien I et al (2012) Aerobic interval training increases peak oxygen uptake more than usual care exercise training in myocardial infarction patients: a randomized controlled study. Clin Rehabil 26:33-44. https://doi. org/10.1177/0269215511405229

47. Revdal A, Hollekim-Strand SM, Ingul CB (2016) Can time efficient exercise improve cardiometabolic risk factors in type 2 diabetes? a pilot study. J Sports Sci Med 15:308-313

48. Little JP, Gillen JB, Percival ME et al (2011) Low-volume highintensity interval training reduces hyperglycemia and increases muscle mitochondrial capacity in patients with type 2 diabetes. J Appl Physiol (Bethesda Md 1985) 111:1554-1560. https://doi. org/10.1152/japplphysiol.00921.2011 